\title{
Lansoprazole Fast Disintegrating Tablet: A New Formulation for an Established Proton Pump Inhibitor
}

\author{
Fabio Baldi a Peter Malfertheiner ${ }^{b}$ \\ a Department of Gastroenterology, Metabolic and Infectious Diseases, S. Orsola-Malpighi Hospital, Bologna, Italy, \\ and ${ }^{\mathrm{b}}$ Department of Gastroenterology, Hepatology and Infectious Diseases, Otto van Guericke University, \\ Magdeburg, Germany
}

\author{
Key Words \\ Acid-related disorders · Lansoprazole · Orally \\ disintegrating tablet $\cdot$ Patient-friendly formulation . \\ Proton pump inhibitor
}

\begin{abstract}
Lansoprazole is a proton pump inhibitor (PPI) which is an effective and well-tolerated treatment option in the management of acid-related disorders. Lansoprazole fast disintegrating tablet (LFDT) - a new, patient-friendly and more convenient formulation of lansoprazole which can be taken with or without water - is the first PPI to be made available as an orally disintegrating tablet. It represents an innovative drug delivery system, comprising enteric-coated microgranules of lansoprazole compressed with an inactive, rapidly dispersing matrix to form a tablet. When the tablet is placed on the tongue and sucked gently it disintegrates rapidly in the mouth, releasing the enteric-coated microgranules which are swallowed with the patient's saliva without water. Alternatively, the tablet can be swallowed with a drink of water. Studies have shown that the bioavailability of LFDT is comparable to lansoprazole capsules, at both 15 and $30 \mathrm{mg}$ doses; the indications and recommended dosages for LFDT are therefore identical to lansoprazole capsules. The new formulation may be of particular ben-
\end{abstract}

efit to those with active life-styles who do not always have water available, patients who have difficulty in swallowing, and elderly patients.

Copyright $@ 2003$ S. Karger AG, Basel

\section{Introduction}

Lansoprazole is a proton pump inhibitor (PPI) which inactivates the final step in the gastric acid secretion pathway in gastric parietal cells in a dose-dependent manner. Bioavailability is $85 \%$ after the first dose - the highest among PPIs [1-5] - and acid inhibition is swift, resulting in rapid relief of symptoms [6]. Lansoprazole also exhibits antibacterial activity against Helicobacter pylori in vitro [7-9].

Seventeen years of clinical experience worldwide have shown lansoprazole to be an effective and well-tolerated treatment option in the management of acid-related disorders, including gastric and duodenal ulcers and gastroesophageal reflux disease, and the treatment or prevention of gastroduodenal lesions induced by NSAIDs [10]. Lansoprazole is also effective in combination with different regimens for $H$. pylori eradication and is included in the first-line PPI-based options for this purpose $[7,8,11-13]$.

\section{KARGER}

Fax +41613061234

E-Mail karger@karger.ch

www.karger.com
(C) 2003 S. Karger AG, Basel

0012-2823/03/0672-0001\$19.50/0

Accessible online at:

www.karger.com/dig
Prof. Fabio Baldi

Department of Gastroenterology, S. Orsola-Malpighi Hospital

Via Massarenti 9, I-40138 Bologna (Italy)

Tel. +39051 6364180, Fax +390514292369

E-Mail Fabio.baldi@orsola-malpighi.med.unibo.it 
Lansoprazole fast disintegrating tablet (LFDT) is an orally disintegrating tablet and is a new, patient-friendly and more convenient formulation of lansoprazole which can be taken with or without water. LFDT, which has an artificial strawberry flavoring, disintegrates rapidly in the mouth and is swallowed easily with the patient's saliva. It is the first PPI that can be taken orally without water. This formulation represents an improved alternative presentation for all patients requiring lansoprazole, offering the benefits of a choice of administration options.

LFDT maintains the same pharmacological properties as lansoprazole capsules and can be taken by any patient who is currently prescribed lansoprazole. The ability to take a tablet either with or without water will offer increased convenience and flexibility - particularly when patients are travelling - and may help to improve compliance in some patients. In addition, LFDT may be suitable for certain groups of patients, such as those with dysphagia associated with gastroesophageal reflux disease [14], odynophagia or strictures, and the elderly or longterm care patients [15].

LFDT is available in Japan and the UK, and will soon become available in the rest of Europe and the USA for use in all lansoprazole indications. This article summarizes the development of LFDT and current clinical experience with the formulation. Potential benefits of LFDT in certain groups of patients are also discussed.

\section{Lansoprazole Capsules}

Lansoprazole is supplied for oral administration with water in capsules, which contain an enteric-coated granule formulation of lansoprazole. The enteric coating protects lansoprazole - which is acid labile - as it passes through the stomach; the coating dissolves in the more neutral conditions of the small intestine, where lansoprazole is absorbed. Absorption is rapid and relatively complete, with the maximum plasma concentration of lansoprazole $\left(\mathrm{C}_{\max }\right)$ occurring within $1.5-2.2 \mathrm{~h}$ after oral dosing and absolute bioavailability ranging from 80 to $91 \%$. Increases in $\mathrm{C}_{\max }$ and the area under the plasma concentration curve (AUC) of lansoprazole are linear over a dose range of 15-60 mg. Lansoprazole does not accumulate and its pharmacokinetics are unaltered by multiple dosing $[7,8]$.

Clinical trials conducted worldwide have demonstrated that lansoprazole is well tolerated by most patients [8] and is widely accepted as a capsule formulation. However, patient compliance with capsules may be affected when patients are away from home and water is not readily available, and in some patients with severe symptoms of odynophagia or dysphagia, such as those with severe reflux esophagitis or esophageal stricture, or in elderly patients.

\section{Lansoprazole Orally Disintegrating Tablet}

LFDT is an orally disintegrating tablet and is a new, patient-friendly formulation that is easy to swallow and can be taken orally with or without water. It has been developed to provide an alternative dosage form and to offer greater flexibility in the prescribing of lansoprazole. LFDT is supplied in blister packs in the same doses as lansoprazole capsules: 15 and $30 \mathrm{mg}$ of lansoprazole per tablet.

LFDT is the first PPI to be made available as an orally disintegrating tablet. Most enteric-coated tablets are formulations of a single unit system; these tend to be small but generally there is a risk that the enteric coat can become damaged during gastric emptying. The drug may then be exposed to acid, which can negatively influence absorption. A small crack or damage to a single unit system may therefore affect the entire dose. Multiple unit systems have been developed to overcome this problem [16]. Common multiple unit systems include capsules containing enteric-coated granules and tablets containing enteric-coated granules. The granules are less likely to be affected by gastric emptying due to their small size [17]; in addition, damage to a single granule will not affect the entire dose. However, capsules and tablets are also considered to be relatively large formulations. LFDT is an improved formulation, containing much smaller microgranules, which disintegrates rapidly in the mouth even without water [unpubl. data].

\section{Easy to Swallow}

LFDT comprises enteric-coated microgranules of lansoprazole compressed with an inactive, rapidly dispersing matrix to form a tablet. A pleasant strawberry flavor may help to stimulate saliva production. When the tablet is placed on the tongue and sucked gently it disintegrates rapidly in the mouth, releasing the enteric-coated microgranules which are swallowed with the patient's saliva without water. Alternatively, the tablet can be swallowed with a drink of water.

In two studies reported by Freston et al. [18], the average disintegration times of LFDT without water were found to be 48 and $53 \mathrm{~s}$ for the $15-$ and $30-\mathrm{mg}$ doses, respectively. 


\section{Innovative Drug Delivery System}

The properties of the microgranules determine the characteristics of the acid resistance system and control the in-vivo performance of LFDT. Each tablet is formed with microgranules that are approximately $330 \mu \mathrm{m}$ in diameter - less than one third of the size of the granules in lansoprazole capsules (approximately 1,100 $\mu \mathrm{m}$ ). Their reduced size allows for a smaller tablet, fast disintegration and an acceptable feel in the mouth. The concentration of enteric-coated microgranules in each tablet affects properties such as hardness, the time of tablet disintegration and acid resistance. In a formulation study, the optimum concentration of microgranules per tablet was found to be $47.4 \%$ to maintain the quality of hardness, the time of disintegration, acid resistance and buffer dissolution [unpubl. data].

Unlike the granules in lansoprazole capsules, which have a core, a lansoprazole layer and a gastroresistant enteric-coating layer, each LFDT microgranule comprises seven layers (fig. 1). The active lansoprazole layer surrounds an inert core, followed by an inert under-coating layer that improves stability in high humidity. Three enteric-coating layers prevent dissolution in the stomach, improve stability, reduce damage during compression and neutralize the taste of the microgranule. An overcoating layer improves the hardness of the tablet [19].

\section{Bioequivalent to Lansoprazole Capsules}

When LFDT disintegrates in the mouth the microgranules are swallowed with the patient's saliva. Lansoprazole is absorbed into the bloodstream after the enteric-coated microgranules dissolve in the neutral conditions of the small intestine.

A bioavailability study has shown that lansoprazole is not absorbed via the oral mucosa during the short time that LFDT is dispersed in the mouth [unpubl. data]. In this single-center, open, crossover study carried out in Japan, 12 healthy adult male volunteers were randomized to receive a single dose of LFDT $30 \mathrm{mg}$, which they either swallowed with water or sucked (to aid dispersal in the oral cavity) and then spat out. A 7-day washout interval separated the two regimens. Very low values were observed for $\mathrm{AUC}_{0-24}$ and $\mathrm{C}_{\max }$ when LFDT was spat out $(8.0 \pm 14.63 \mathrm{~h} \cdot \mathrm{ng} / \mathrm{ml}$ and $6.8 \pm 10.52 \mathrm{ng} / \mathrm{ml})$ compared with LFDT swallowed with water $(1,910.9 \pm 546.02 \mathrm{~h}$. $\mathrm{ng} / \mathrm{ml}$ and $978.8 \pm 401.62 \mathrm{ng} / \mathrm{ml})$. In addition, almost $100 \%$ recovery of lansoprazole in the dispersed microgranules was observed.

Studies have shown that the bioavailability of LFDT is comparable to lansoprazole capsules - at both 15 and

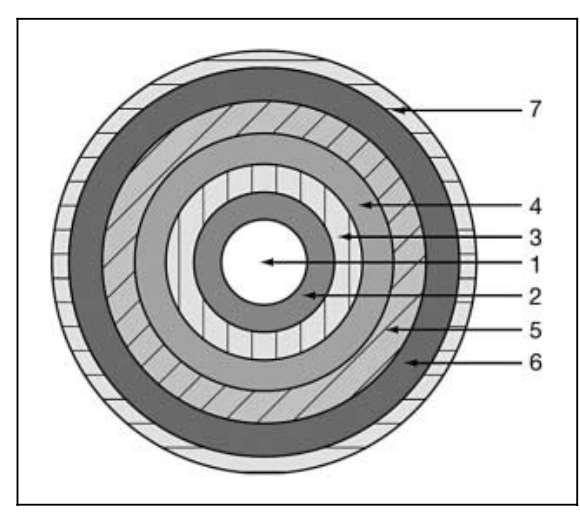

Fig. 1. Structure/composition of enteric-coated microgranules used to make LFDT (thickness of each layer is not to scale). 1 = Inert core; 2 = lansoprazole layer; 3 = under-coating layer - improves stability in high humidity; $4=1$ st enteric-coating layer - improves stability of lansoprazole; $5=2$ nd enteric-coating layer - prevents breakage of the enteric coats during tablet compression; $6=3$ rd enteric-coating layer - neutralizes taste of microgranule; $7=$ over-coating layer - improves tablet hardness.

$30 \mathrm{mg}$ doses - such that its effect, in terms of efficacy and safety, will be the same. The indications and recommended dosages for LFDT are therefore identical to lansoprazole capsules.

In two studies reported by Freston et al. [18], the safety and bioavailability of LFDT taken without water were compared with lansoprazole capsules after a single dose of 15 or $30 \mathrm{mg}$. Each study enrolled 60 healthy adults and utilized a randomized, single-center, two-period, crossover design with a 7-day washout interval. The mean plasma concentration profiles were comparable for LFDT and lansoprazole capsules at both $15-$ and $30-\mathrm{mg}$ doses (fig. 2). The $90 \%$ confidence levels for $\mathrm{C}_{\max }$ and $\mathrm{AUC}_{\infty}$ were within the $0.80-1.25$ range (table 1), indicating that LFDT was bioequivalent to lansoprazole capsules at 15and 30-mg doses. Both LFDT and lansoprazole capsules were safe and well tolerated.

Two single-center, open, crossover studies in Japan demonstrated bioequivalence between LFDT taken without water and lansoprazole capsules, at both 15- and 30$\mathrm{mg}$ doses [unpubl. data]. Twenty-four healthy adult males were randomized to receive a single dose of LFDT (15 or $30 \mathrm{mg}$ ), sucked and swallowed without water, or lansoprazole capsule (15 or $30 \mathrm{mg}$ ), with a 7-day washout interval. The results for LFDT $15 \mathrm{mg}$ without water versus lansoprazole capsule $15 \mathrm{mg}$ were as follows: $\mathrm{AUC}_{0-24}$ values were $1,105.3 \pm 1,101.40$ vs. $1,136.2 \pm 1,186.29 \mathrm{~h} \cdot \mathrm{ng} / \mathrm{ml}$ (geometric mean ratio $0.98 ; 90 \%$ confidence interval, 


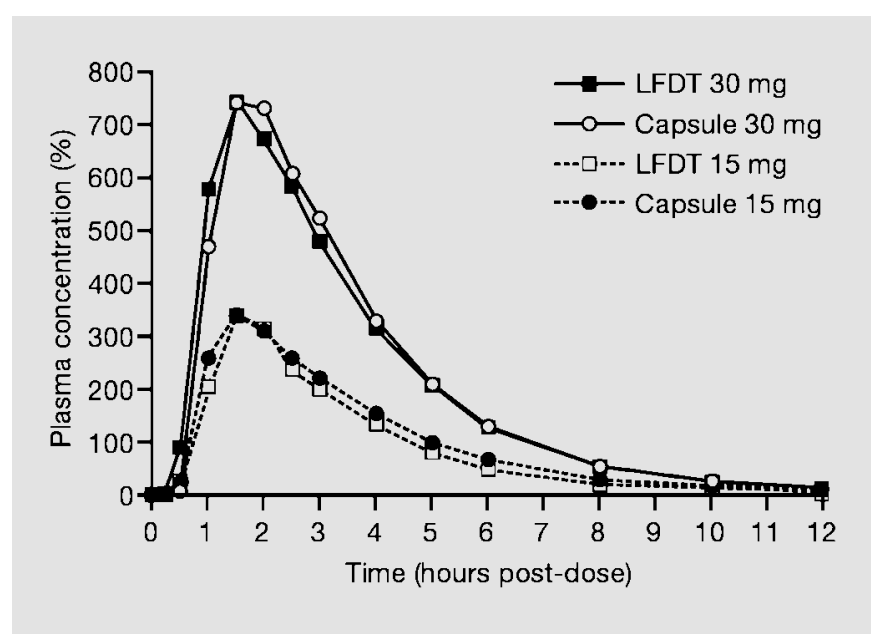

Fig. 2. Comparison of mean lansoprazole plasma concentration time profiles between LFDT and lansoprazole capsule at 15- and 30-mg doses (data from Freston et al. [18]).

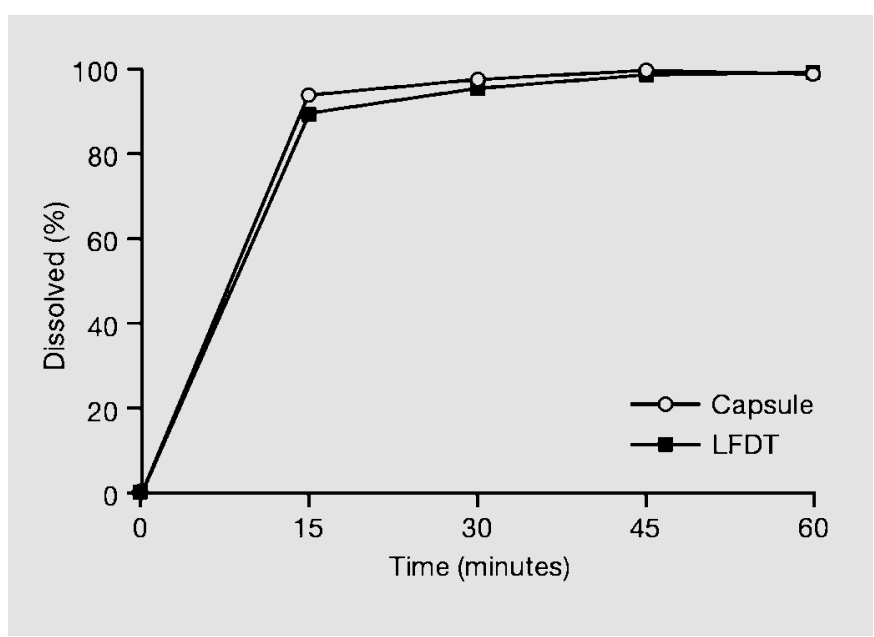

Fig. 3. Comparison of dissolution profiles between LFDT $30 \mathrm{mg}$ and lansoprazole capsule $30 \mathrm{mg}$ at buffer stage after a 60-min acid resistance test.
Table 1. Relative bioavailability of LFDT versus lansoprazole capsules at 15 - and 30-mg doses (data from Freston et al. [18])

\begin{tabular}{|c|c|c|c|c|}
\hline \multirow{2}{*}{$\begin{array}{l}\text { Pharmacokinetic } \\
\text { parameters }\end{array}$} & \multicolumn{2}{|l|}{$15 \mathrm{mg}$} & \multicolumn{2}{|l|}{$30 \mathrm{mg}$} \\
\hline & point estimate & $90 \% \mathrm{CI}$ & point estimate & $90 \% \mathrm{CI}$ \\
\hline $\mathrm{C}_{\max }$ & 1.059 & $0.909-1.235$ & 1.089 & $0.958-1.238$ \\
\hline $\mathrm{AUC}_{\mathrm{I}}$ & 1.042 & $0.932-1.164$ & 0.992 & $0.900-1.092$ \\
\hline $\mathrm{AUC}_{\infty}$ & 1.033 & $0.928-1.150$ & 0.988 & $0.900-1.083$ \\
\hline
\end{tabular}

0.89-1.07) and $C_{\max }$ values were $474.1 \pm 254.04$ versus $442.7 \pm 231.71 \mathrm{ng} / \mathrm{ml}$ (geometric mean ratio $1.03 ; 90 \%$ confidence interval, 0.87-1.22). The results for LFDT $30 \mathrm{mg}$ dispersed versus lansoprazole capsule $30 \mathrm{mg}$ were as follows: $\mathrm{AUC}_{0-24}$ values were $2,216.5 \pm 1,270.16$ versus $2,223.6 \pm 1,203.07 \mathrm{~h} \cdot \mathrm{ng} / \mathrm{ml}$ (geometric mean ratio $0.98 ; 90 \%$ confidence interval, $0.91-1.06)$ and $\mathrm{C}_{\max }$ values were $992.8 \pm 384.34$ versus $949.2 \pm 361.68 \mathrm{ng} / \mathrm{ml}$ (geometric mean ratio $1.04 ; 90 \%$ confidence interval, 0.90-1.20).

A second single-center, open, randomized, crossover study in Japan has shown that the bioavailability of lansoprazole was similar after the administration of LFDT $30 \mathrm{mg}$ with and without water [unpubl. data].

LFDT has similar dissolution characteristics to lansoprazole capsules [unpubl. data] (fig. 3).

\section{Clinical Experience}

\section{Patient Acceptability}

LFDT represents a new treatment option for all patients with acid-related disorders, offering a choice of administration. This may be especially useful for those with active life-styles who do not always have water available or those who find capsules and tablets difficult to swallow.

A patient acceptability study evaluated patient reactions to the taste of LFDT and their opinions on convenience and the likelihood that they would request LFDT from their physician [unpubl. data]. General practitioners in the UK recruited 156 patients who were already prescribed lansoprazole $30 \mathrm{mg}$, who were randomized to take LFDT $30 \mathrm{mg}$ either swallowed with water or sucked and swallowed without water for 2 days. Patients switched their method of administration on days 3 and 4 and could choose whether to take LFDT with or without water on days 5-7. 
The majority of patients found the flavor of the tablets acceptable (94 vs. $83 \%$ patients taking LFDT with and without water, respectively). Similarly, the majority of patients had no problems taking the tablets either with water $(91 \%)$ or without water $(96 \%)$. The results indicated that while many patients would prefer to take LFDT with water when at home, many would also prefer to take LFDT without water when on holiday, travelling, out shopping or out with friends. In the subgroup of patients who chose to take LFDT without water on days 5-7, 88\% said they were very likely to ask their physician for the new formulation. All patients were confident that their medication would be effective, whether in the form of lansoprazole capsules or LFDT taken with or without water.

\section{Conclusion}

LFDT is the first PPI that can be taken without water. It is an innovative, patient-friendly formulation with a pleasant strawberry flavor, which disintegrates rapidly in the mouth and is swallowed with the patient's saliva without water. Alternatively, the tablet can be swallowed with a drink of water. LFDT is bioequivalent to lansoprazole capsules and has identical indications and recommended dosages. The new formulation will offer greater flexibility in the prescribing of lansoprazole, may improve patient compliance with treatment, and may be of particular benefit to patients who have difficulty in swallowing and elderly patients. Future studies, comparing the two lansoprazole formulations in different clinical settings, will provide more information on the real advantages offered by LFDT.

\section{References}

1 Tolman KG, Sanders SW, Buchi KN, Karol MD, Jennings DE, Ringham GL: The effects of oral doses of lansoprazole and omeprazole on gastric pH. J Clin Gastroenterol 1997;24:6570 .

2 Fitton A, Wiseman L: Pantoprazole. A review of its pharmacological properties and therapeutic use in acid-related disorders. Drugs 1996;51:460-482.

3 Hassan-Alin M, Andersson T, Bredgerg E, Röhss K: Pharmacokinetics of esomeprazole after oral and intravenous administration of single and repeated doses to healthy subjects. Eur J Clin Pharmacol 2000;56:665-670.

4 Swan SK, Hoyumpa AM, Merritt GJ: Review article: The pharmacokinetics of rabeprazole in health and disease. Aliment Pharmacol Ther 1999;13(suppl 3):11-17.

5 Howden CW: Clinical pharmacology of omeprazole. Clin Pharmacokinet 1991;20:38-49.

6 Richter JE, Kahrilas PJ, Sontag SJ, Kovacs TO, Huang B, Pencyla JL: Comparing lansoprazole and omeprazole in onset of heartburn relief: Results of a randomized, controlled trial in erosive esophagitis patients. Am J Gastroenterol 2001;96:3089-3098.

7 Matheson AJ, Jarvis B: Lansoprazole. An update of its place in the management of acidrelated disorders. Drugs 2001;61:1801-1833.
8 Bown RL: An overview of the pharmacology, efficacy, safety and cost-effectiveness of lansoprazole. Int J Clin Pract 2002;56:132-139.

9 Nakao M, Malfertheiner P: Growth inhibitory and bactericidal activities of lansoprazole compared with those of omeprazole and pantoprazole against Helicobacter pylori. Helicobacter 1998;3:21-27.

10 Lai KC, Lam SK, Chu KM, Wong BCY, Hui WM, Hu WHC, Lau GKK, Wong WM, Yuen MF, Chan AOO, Lai CL, Wong J: Lansoprazole for the prevention of recurrences of ulcer complications from long-term low-dose aspirin use. N Engl J Med 2002;346:2033-2038.

11 Malfertheiner P, Megraud F, O'Morain C, Hungin AP, Jones R, Axon A, Graham DY, Tytgat G; The European Helicobacter pylori Study Group (EHPSG): Current concepts in the management of Helicobacter pylori infection - The Maastricht 2-2000 Consensus Report. Aliment Pharmacol Ther 2002;16:167180.

12 Misiewicz JJ, Harris AW, Bardhan KD, Levi S, O’Morain C, Cooper BT, Kerr GD, Dixon MF, Langworthy H, Piper D: One week triple therapy for Helicobacter pylori: A multicentre comparative study. Lansoprazole Helicobacter Study Group. Gut 1997;41:735-739.
13 Pilotto A, Franceschi M, Leandro G, Bozzola L, Fortnato A, Rassu M, Meli S, Soffiati G, Scagnelli M, Di Mario F, Valerio G: Efficacy of 7 day lansoprazole-based triple therapy for $\mathrm{He}$ licobacter pylori infection in elderly patients. $\mathrm{J}$ Gastroenterol Hepatol 1999; 14:468-475.

14 Patti MG, Feo CV, De Pinto M, Arcerito M, Tong J, Gantert W, Tyrrell D, Way LW: Results of laparoscopic antireflux surgery for dysphagia and gastroesophageal reflux disease. Am J Surg 1998;176:564-568.

15 Friedel D, Fisher RS: Gastrointestinal motility in the elderly. Clin Geriatr 2000;8:30-43.

16 Tateno M, Nakamura N: Phase I study of lansoprazole (AG-1749) antiulcer agent - Capsule form. J Clin Ther Med 1991;7:51-62.

17 Tabata T, Kashihara T, Hirai S, Kitanori N, Toguchi H: Effect of gastric $\mathrm{pH}$ on the absorption of a new antiulcer drug (lansoprazole) in the beagle dog. J Biopharm Sci 1991;2:319328.

18 Freston JW, Chiu YL, Mulford DJ, Ballard ED: Comparative pharmacokinetics and safety of lansoprazole oral capsules and orally disintegrating tablets in healthy subjects. Aliment Pharmacol Ther 2003;17:361-367.

19 Shimizu T, Nakano Y, Tabata T, Hamaguchi N: 19th Symposium on Particulate Preparations and Designs. October 2002, abstract A23. 